\title{
The LBNL/JSU/AGMUS \\ Science Consortium
}

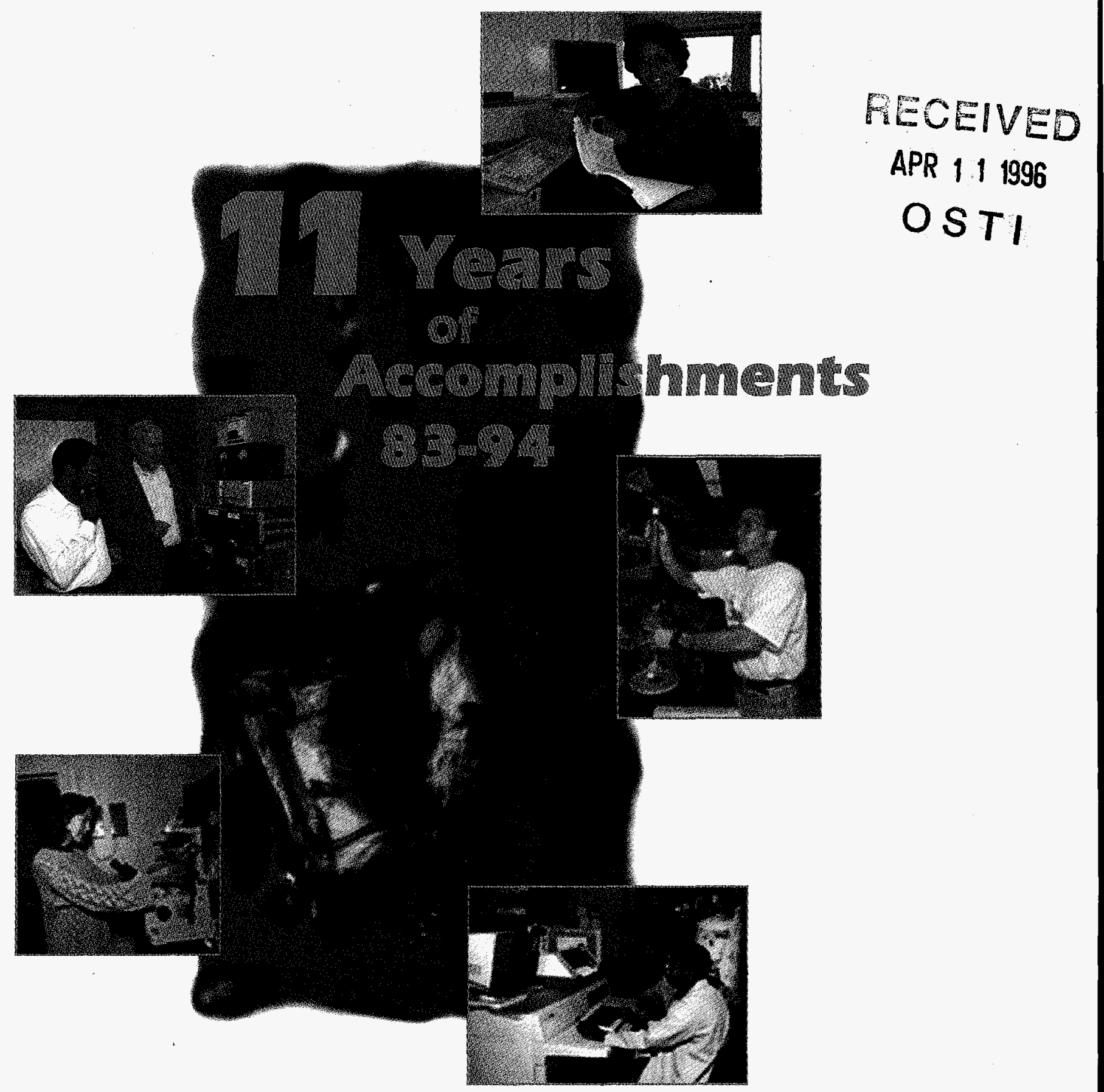

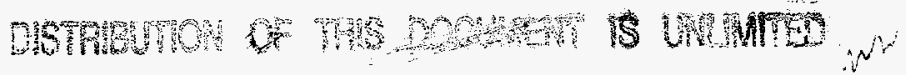


The Lawrence Berkeley National Laboratory/Jackson State University/Ana G. Méndez University System Science Consortium is supported by the Office of University and Science Education Programs, U.S. Department of Energy, under Contract DE-AC03-76SF00098. 


\section{DISCLAMMER}

Portions of this document may be illegible in electronic image products. Images are produced from the best available original document. 


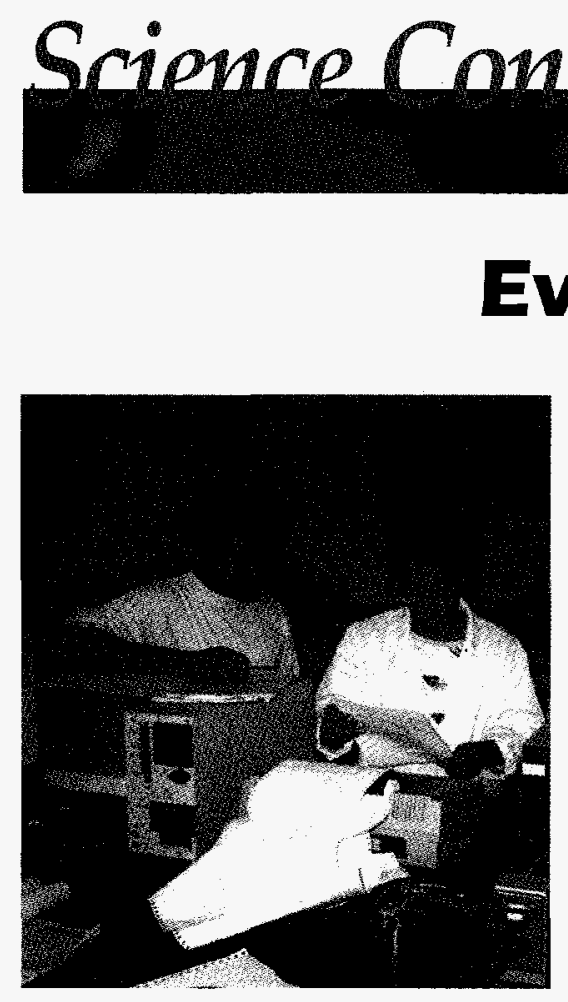

Below, Cedric Buckley, JSU graduate, currently at Michigan State University-East Lansing Graduate School.
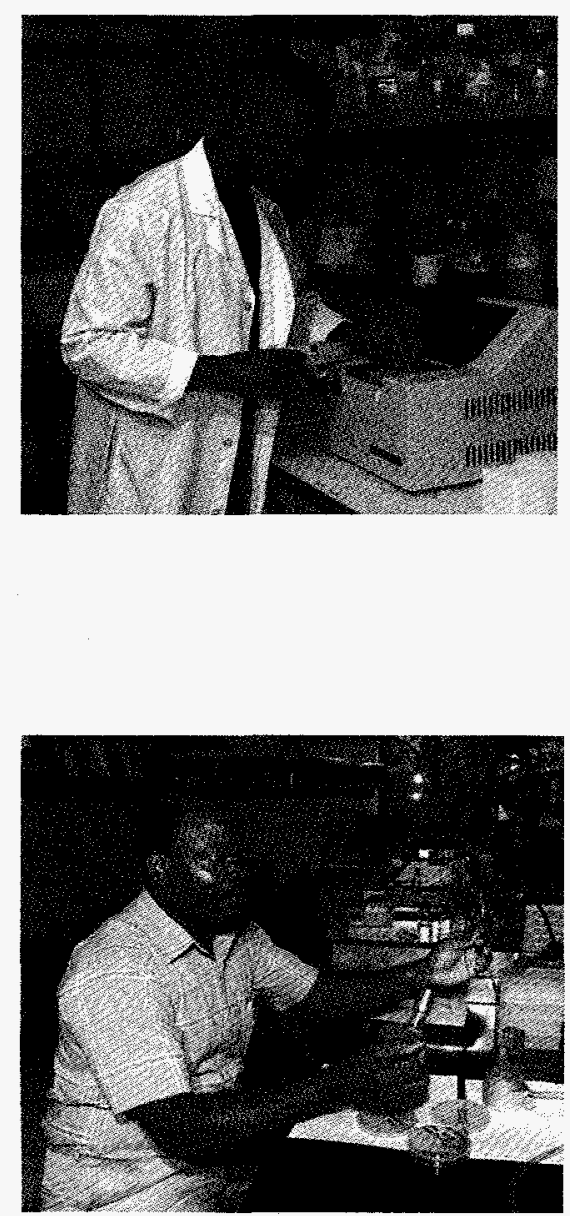

Left, Andrés Polanco, AGMUS graduate, now a toxicology student at Universidad de Puerto Rico, Medical Campus.

Right, Melanie Ratliff, JSU graduate, will begin graduate studies at the University of Illinois in the Fall of 1995.

Right, Jeanette Gómez, AGMUS graduate, now a graduate student of toxicology at Univ. of Pittsburgh.

Right, Ricardo Pérez, AGMUS alumnus, now a graduate student at Universidad de Puerto Rico, Medical Sciences campus.

Left, Stephen Ekunwe, a JSU alumnus, now a graduate student Michigan State University-East Lansing.
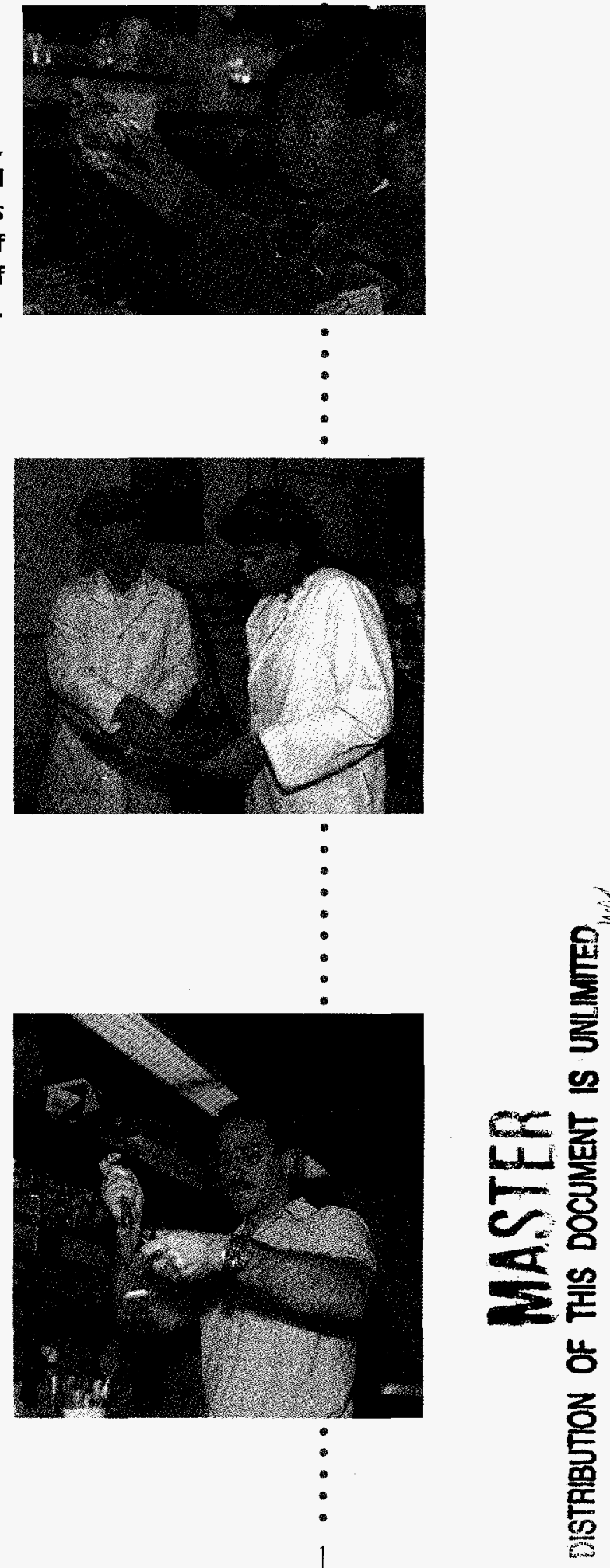


\section{The LBNLJSU/AGMUS Science Consortium}

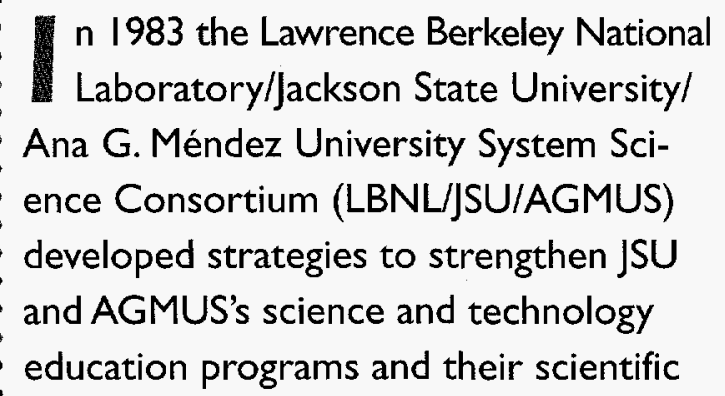

n 1983 the Lawrence Berkeley National Laboratory/Jackson State University/ Ana G. Méndez University System Science Consortium (LBNL/JSU/AGMUS) developed strategies to strengthen JSU and AGMUS's science and technology education programs and their scientific

research capacities. Today the Science Consortium has surpassed its goals and is now prepared to assist other minority institutions. We plan to do this with the help of information networks, such as the World Wide Web, and through formal partnerships.
Right, Lawrence Berkeley National Laboratory,

Berkeley, California, on the hills behind the campus of the University of California at Berkeley.

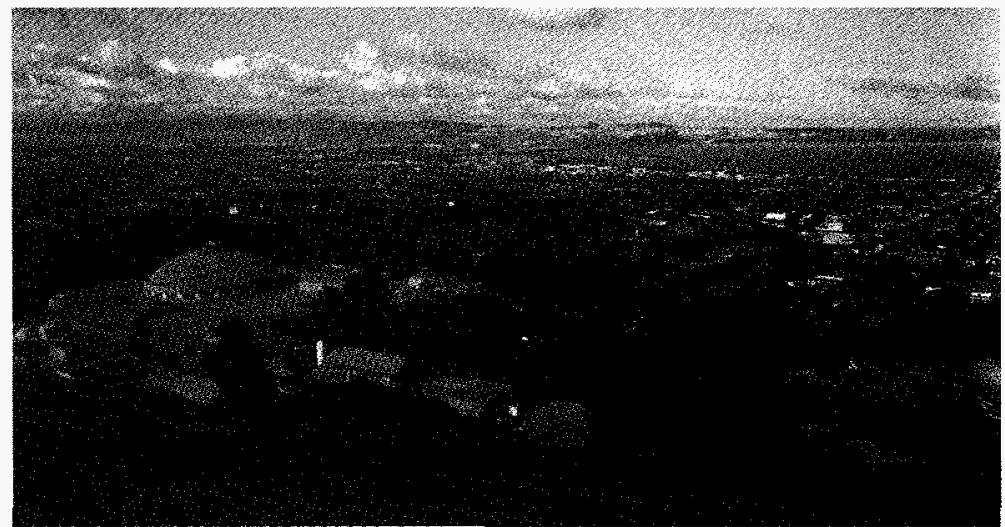

Left, Science Education \& Research building, recently built, at Universidad Metropolitana, one of the schools that constitute the Ana G. Méndez University System in Rio Piedras, Puerto Rico.
Right, The John Peoples building, where several departments of the School of Science \& Technology are housed-Jackson State University, Jackson, Mississippi.

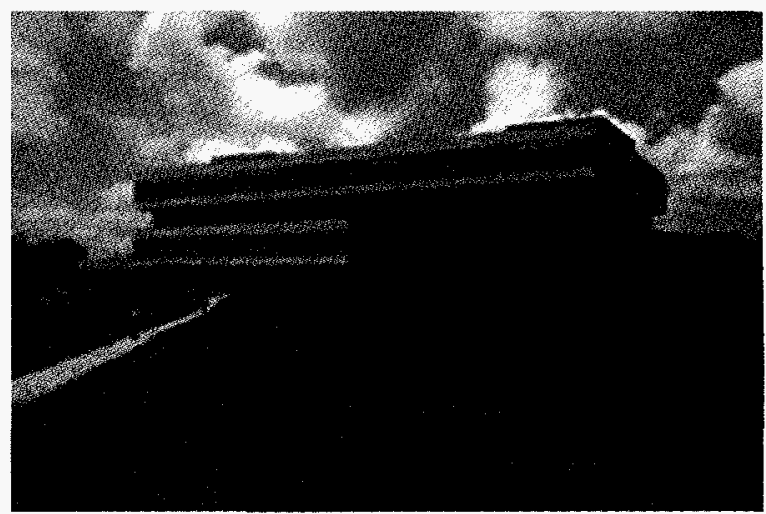


The Science Consortium reaches out : information networks :

\section{to others through :}

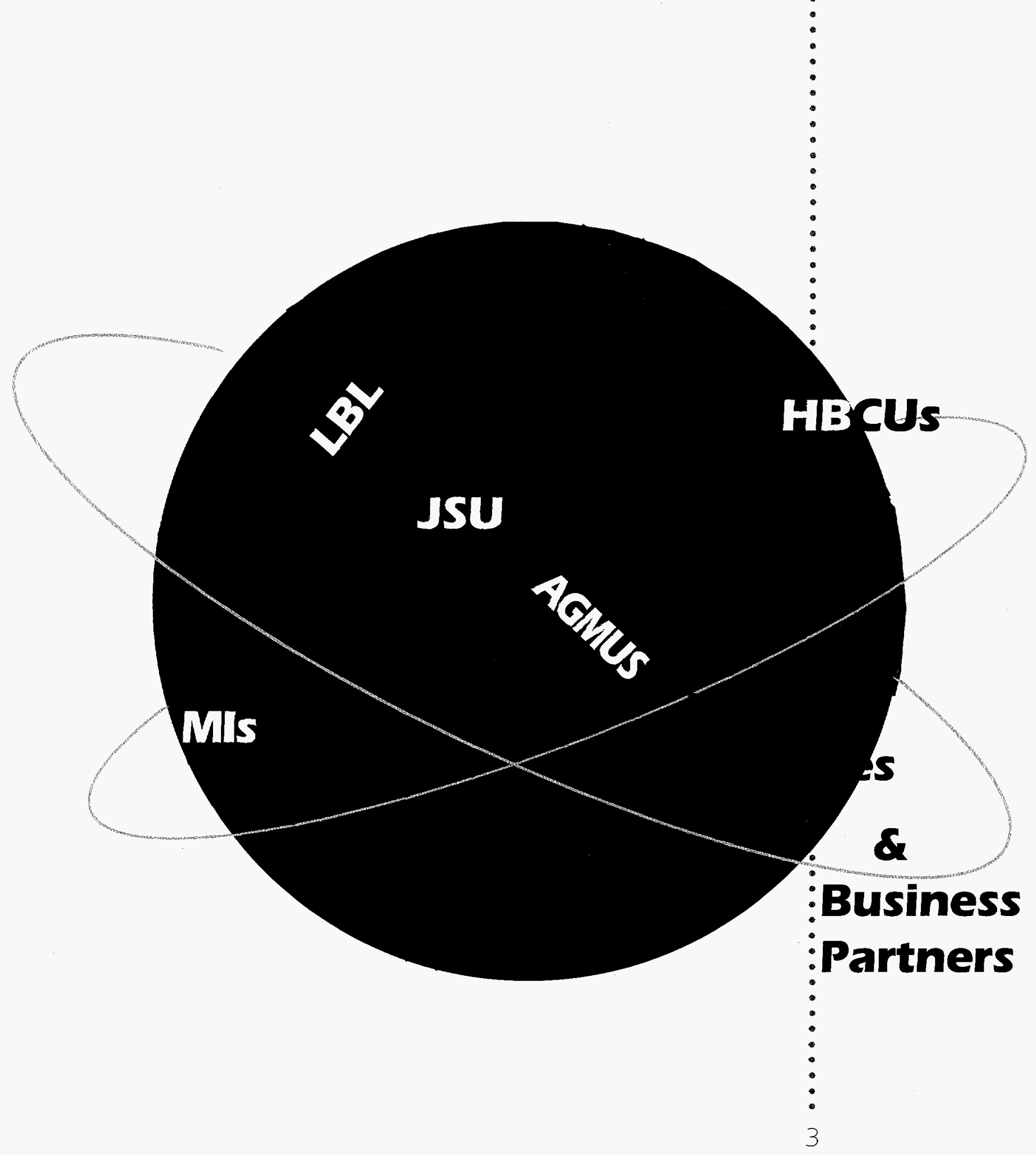




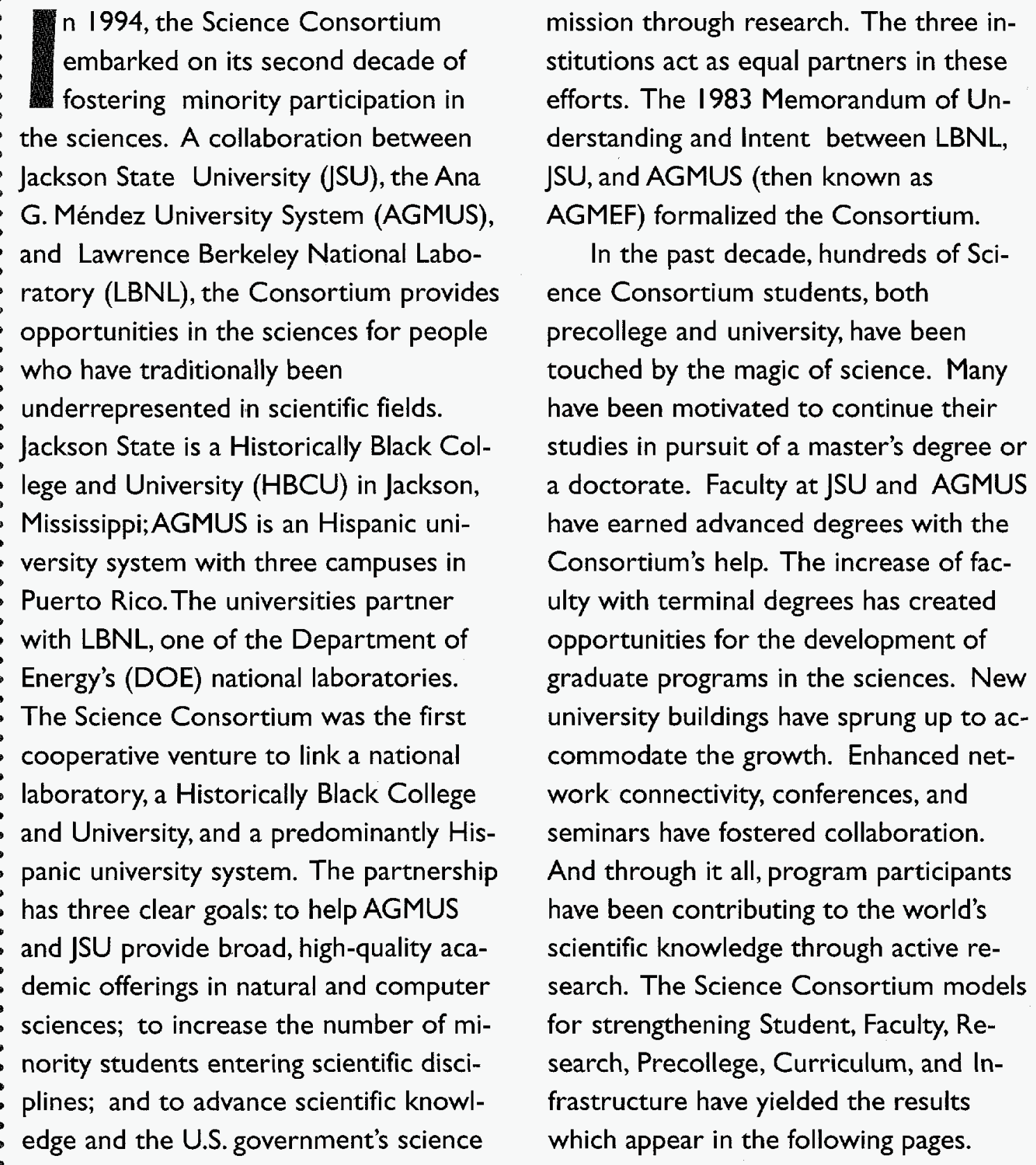





\section{Student Development Accomplishments}

- Eigteen students are presently pursuing Ph.D degrees.

- Presently there are 17 Science Consortium students pursing an M.S. degree.

- Several majority graduate schools are committed to enrolling Science Consortium students

- More than 300 students have received support for research at their school.

- More than 250 student research ap- pointments at Lawrence Berkeley National Laboratory

- Fifty five students have received consortium support to pursue Master's degrees

- Since 1990, over 250 students have participated in national science research conferences

- Several students have co-authored articles in scientific professional journals.
"It gave me the confidence and maturity I needed to continue my studies. It was definitely of major influence on my decision to continue graduate studies."

- Luis Benítez

Bibiloni, Universidad del Turabo graduate, doctor of veterinary medicine. Htrs!.

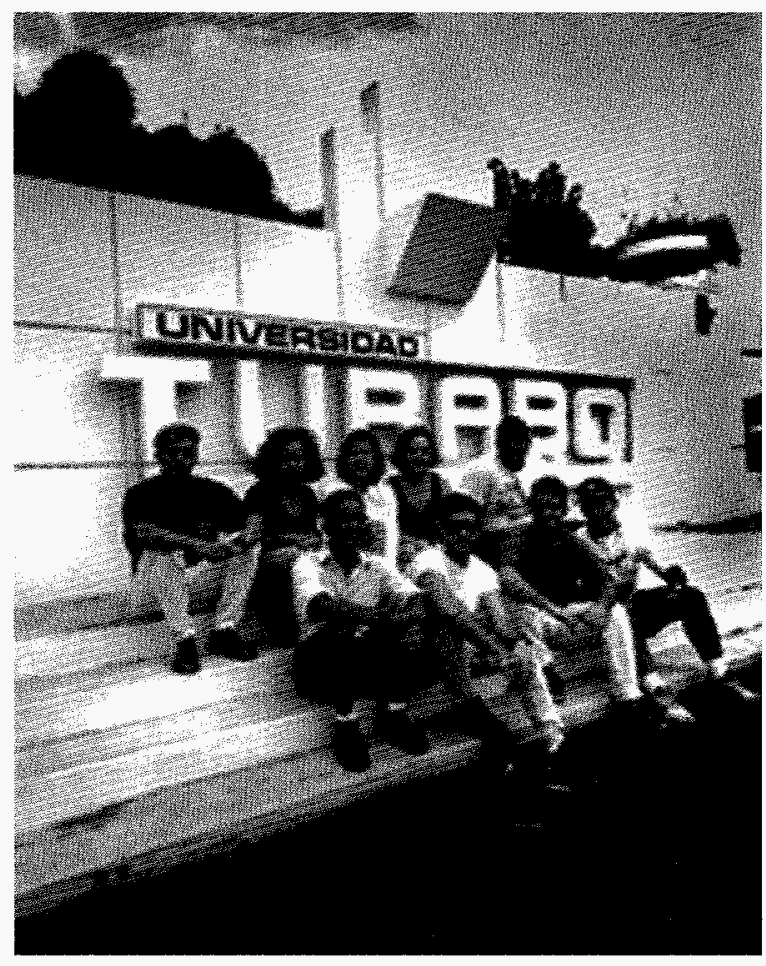

Main entrance of Universidad del Turabo. 


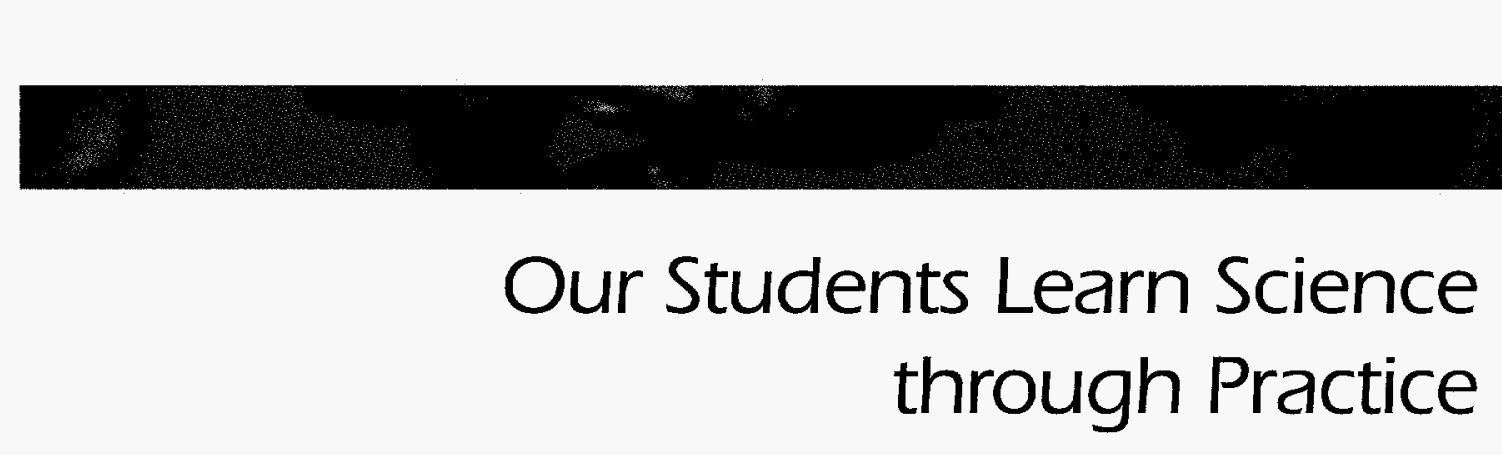

Accomplishments

Right, JSU student Louis Hall at JSU with Prof.Balwant Sekhon.

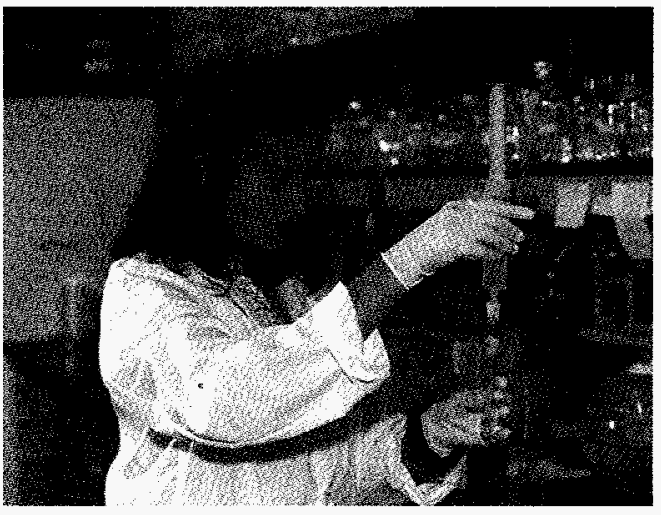

Left, Betsy Martínez, AGMUS student at Universidad del Turabo, at work in Dr. Leighton's U.C. Berkeley laboratory. Betsy will be entering the University of Minnesota on full scholarship in the fall of 1995.

Right, JSU student at JSU

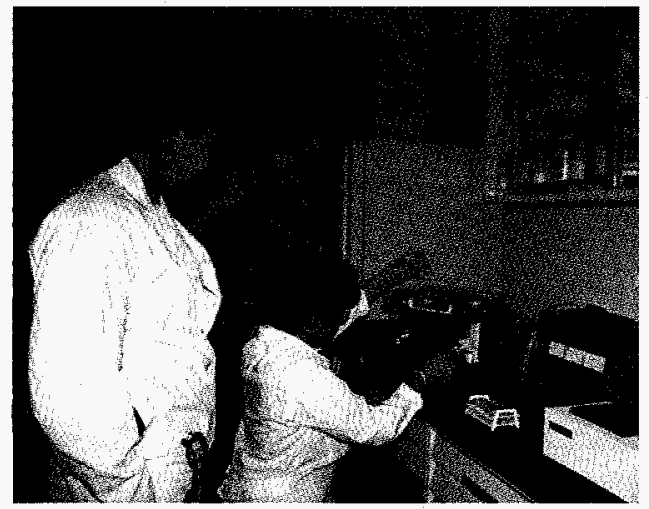

Left, AGMUS students in Bioremediation Environmental Science research laboratory, Lawrence Berkeley Laboratory, with Dr. Edgar Resto, a professor at Universidad del Turabo.

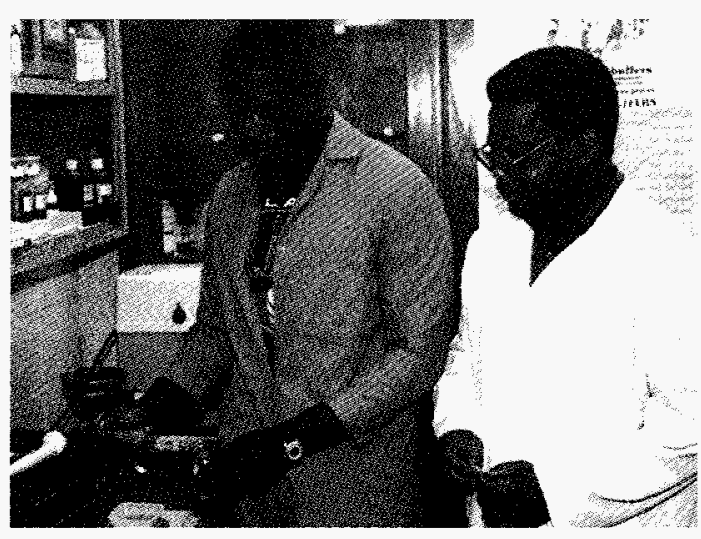




\section{Faculty Development}

hrough its faculty development activities, the Science Consortium has helped to increase faculty members' capability to teach and perform research. All the institutions of the Consortium have benefited from the resulting relationships between LBNL, JSU, and AGMUS scientists.

In 1983, only two science faculty member from AGMUS held a Ph.D. Now, $35 \%$ of the science faculty hold a doctorate in either - natural or allied health sciences. Also, in the past decade, the proportion of JSU

- faculty members

- holding doctorates was brought up to - more than three fourths. Participation - in workshops and conferences has also - blossomed. In the last decade, 129 fac- ulty members have attended 175 profes- sional conferences, 102 have participated in 106 specialized workshops, and 113 - have made presentations at professional meetings. Research opportunities at LBNL have contributed significantly to several instructors' participation in scientific training and research. Some $57 \mathrm{fac}$ ulty members from the Consortium's schools have taken advantage of the chance to work at a distinguished scientific institution. The laboratory also lends equipment and provides consultants to aid Consortium faculty in developing their own laboratories.

- Over 75 publications have been published in refereed journals.

- Collaborative research has resulted in AGMUS and JSU faculty receiving support from other federal agencies and business and industry.

- Faculty are now skilled in using information networks and have included them in their collaborative research and student development activities.

- More than 57 faculty have worked at national laboratories. 


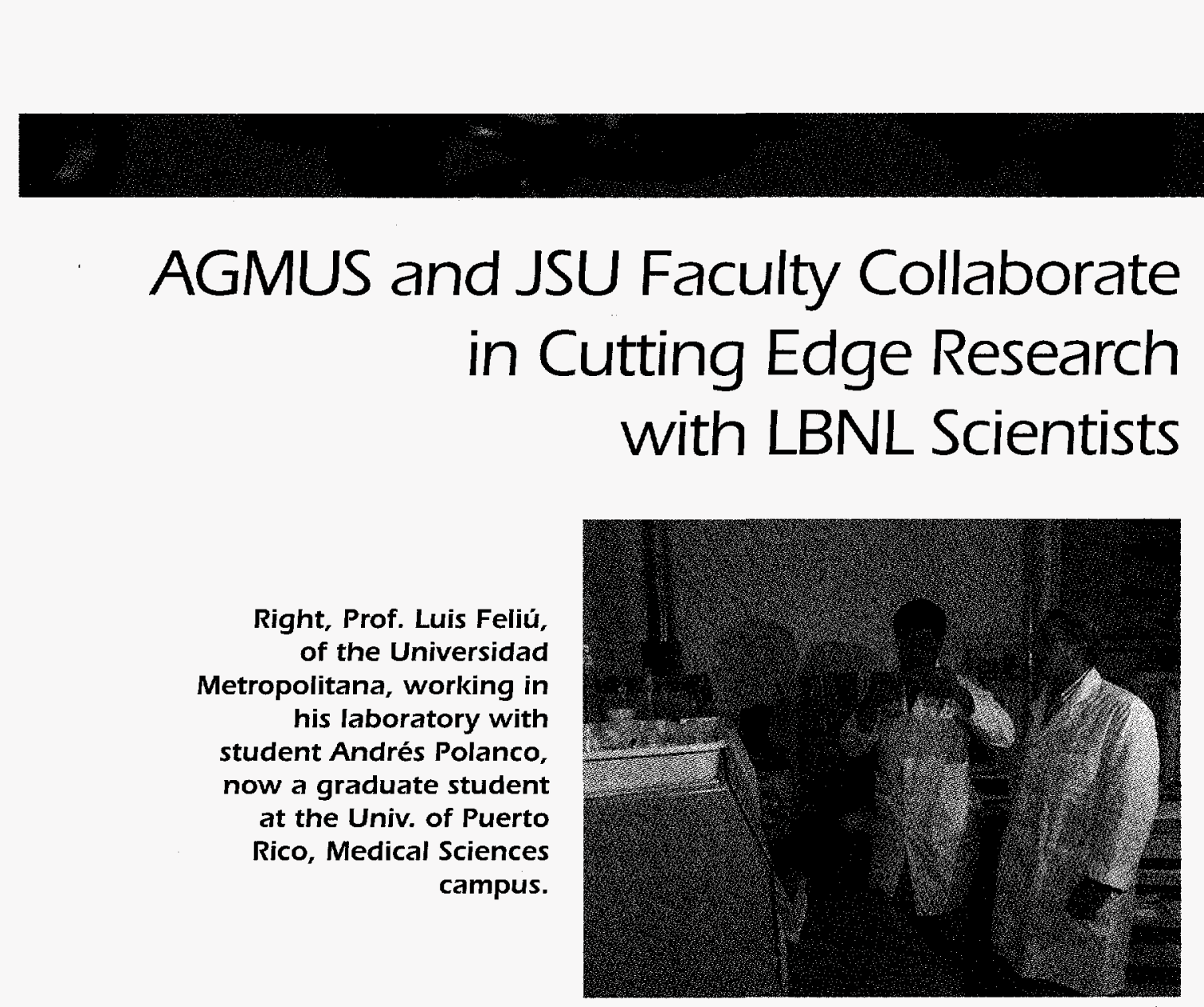

Accomplishments

\section{AGMUS and JSU Faculty Collaborate in Cutting Edge Research with LBNL Scientists}

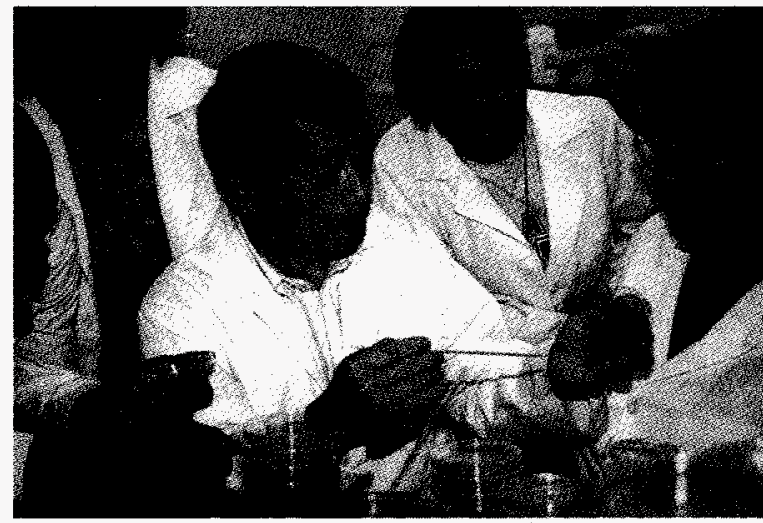

Left, Prof. W.-S. Yang.

of the Biology

Department at JSU

teaching in his

laboratory.

Right, Dr. Fred Nelson, JSU

professor, mentoring two graduate students.

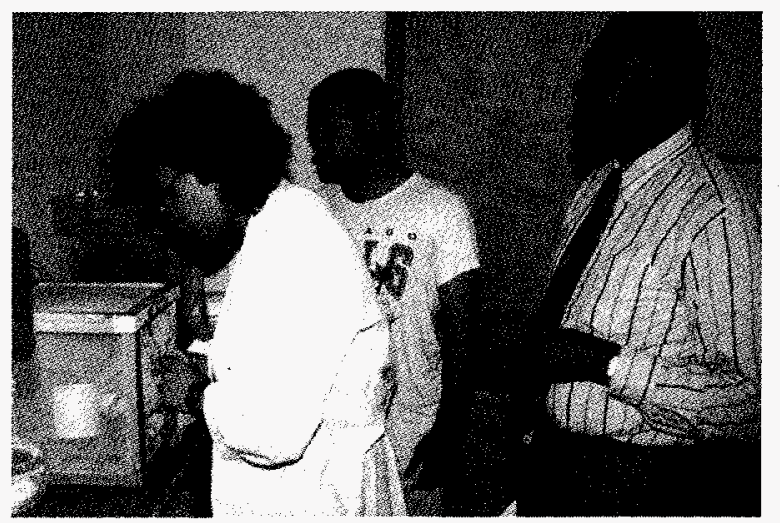

"It is just a matter of being exposed to the pertinent information, and also having a mentor willing to teach one how to do science."

- Stephen

Ekunwe, JSU Graduate, Ph.D. student at Michigan State University.

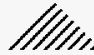




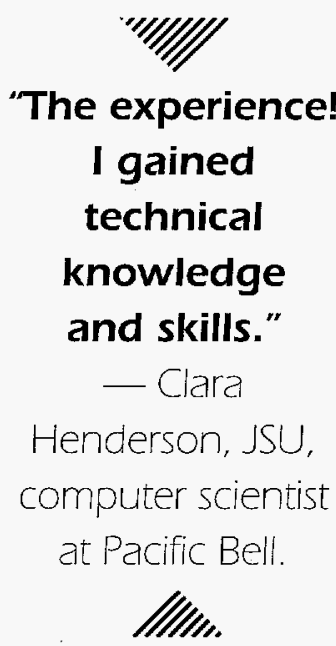

"The experience! I gained technical knowledge and skills."

Henderson, JSU, computer scientist

\section{Research}

esearch is at the core of the Science

Consortiurn's activities. Students as

well as faculty members participated in re-

search projects. This work is directed to-

ward strengthening and expanding the energy and environment related research capabilities of LBNL, JSU, and AGMUS. The Consortium schools had little research capability when the consortium was founded. Jackson State University conducted little energy research, and its participation in collaborative projects was limited. At AGMUS, no research was conducted in science or computer science. All of this changed with the efforts of the Science Consortium. Scientific collaborations between the universities and LBNL have received national recognition, and some have earned followon research grants from federal agencies. AGMUS' initiatives to increase the amount and quality of research include: workshops in the use of the Internet for research, technical manuscript preparation, monthly journal club, and establishment of an external research committee for the selection of research projects.

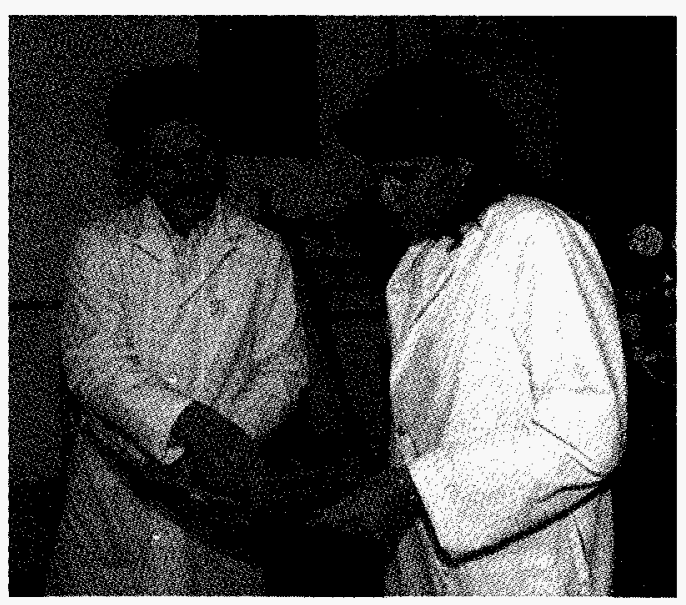

Above, LBNL researcher, Rolf Melhorn, with Ms. Jeanette Gómez in Dr. Melhorn's lab during the 1991 summer internship program.

\section{Examples of our Successful Collaborative and Campus Research Activities}

- Luis Feliú (AGMUS/UMET), Dale Perry (LBNL), and Andrés Polanco (UMET), Vibrational Spectroscopic Studies, $\mathrm{Pa}$ per selected as one of the top ten best for the 1993, and 1994 ACS Conferences.

- Bob Buchanan (UCB/LBNL), Terrance Leighton (UCB/LBNL), Wen Sun-Yung (JSU) collaborating on the BEST Project

- Rolf Melhorn (LBNL), Jeanette Gómez (AGMUS graduate), collaborating on the BEST Project. Ms. Gómez has since been admitted to University of Pittsburgh's Graduate School program in toxicology. She has been acknowledged as one of the two top graduate researchers in her department.

- Bill Johnston (LBNL) \& Keshea Williams (JSU student), collaborating on the Whole Frog Project. Developed computer model of frog dissection for current teaching of biology through the World Wide Web. 


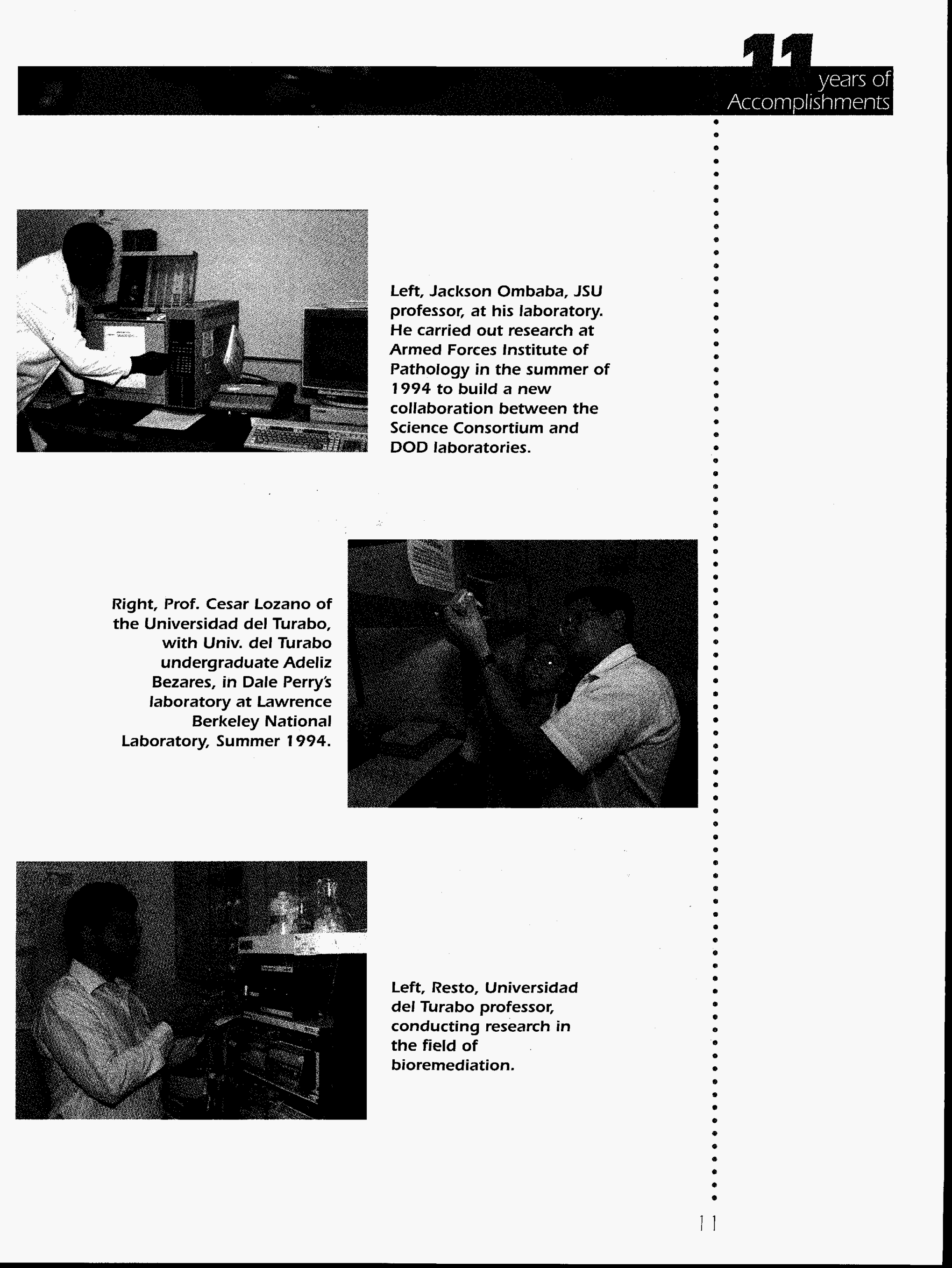




\section{The BEST Program}

Wioremediation Education, Science and Technology (BEST) project is the first independent program to grow out of the efforts of the Science Consortium. BEST was established in 1992 to provide opportunities in the interdisciplinary field of bioremediation. It addresses two national needs: educating researchers to develop innovative methods of waste management and increasing the representation of women and underrepresented minorities in cutting-edge science.

The idea of establishing centers for

bioremediation education - and research came out of a collaboration between - investigators at the University of California, Berkeley (UC Berkeley) and the schools of the Science

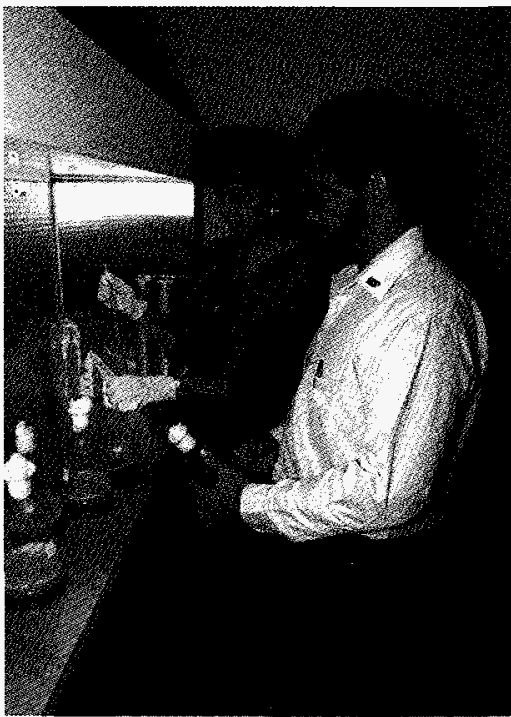

Above, Edgar Resto at LBNL with BEST student. cal environment. At UC Berkeley, research is focused on the problems of the San Francisco Bay area, including removal of toxic metals from San Francisco Bay and the Kesterson Reservoir region. Work at JSU focuses on pollution in the Mississippi River, including metallic contaminants that originate in neighboring industrial areas. The center at AGMUS conducts research on the environmental problems of Lake Cidra and San Juan Bay, both of which receive pollutants from the surrounding industrial areas. It will also develop new methodologies for the analysis of toxic pollutants, bot organic and metallic.

Consortium. The participating scientists

found evidence for the usefulness of a new

approach to toxic metal bioremediation.

- The centers were started to fulfill the promise of the new technique and develop other waste management solutions.

BEST centers have been established at the participating institutions. Each one addresses the bioremediation needs of its lo-

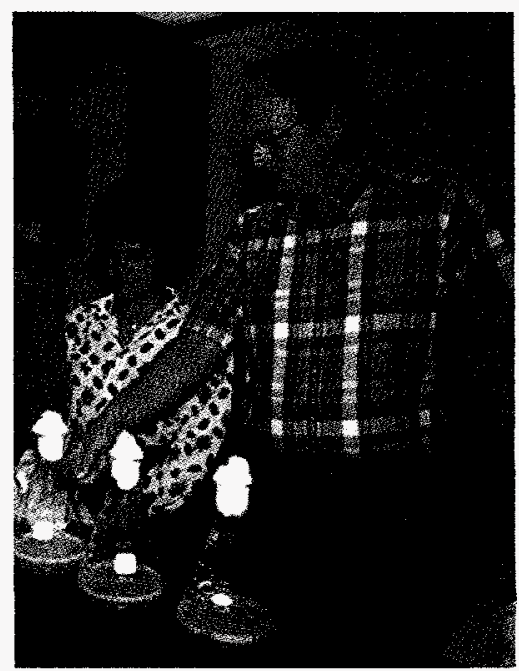



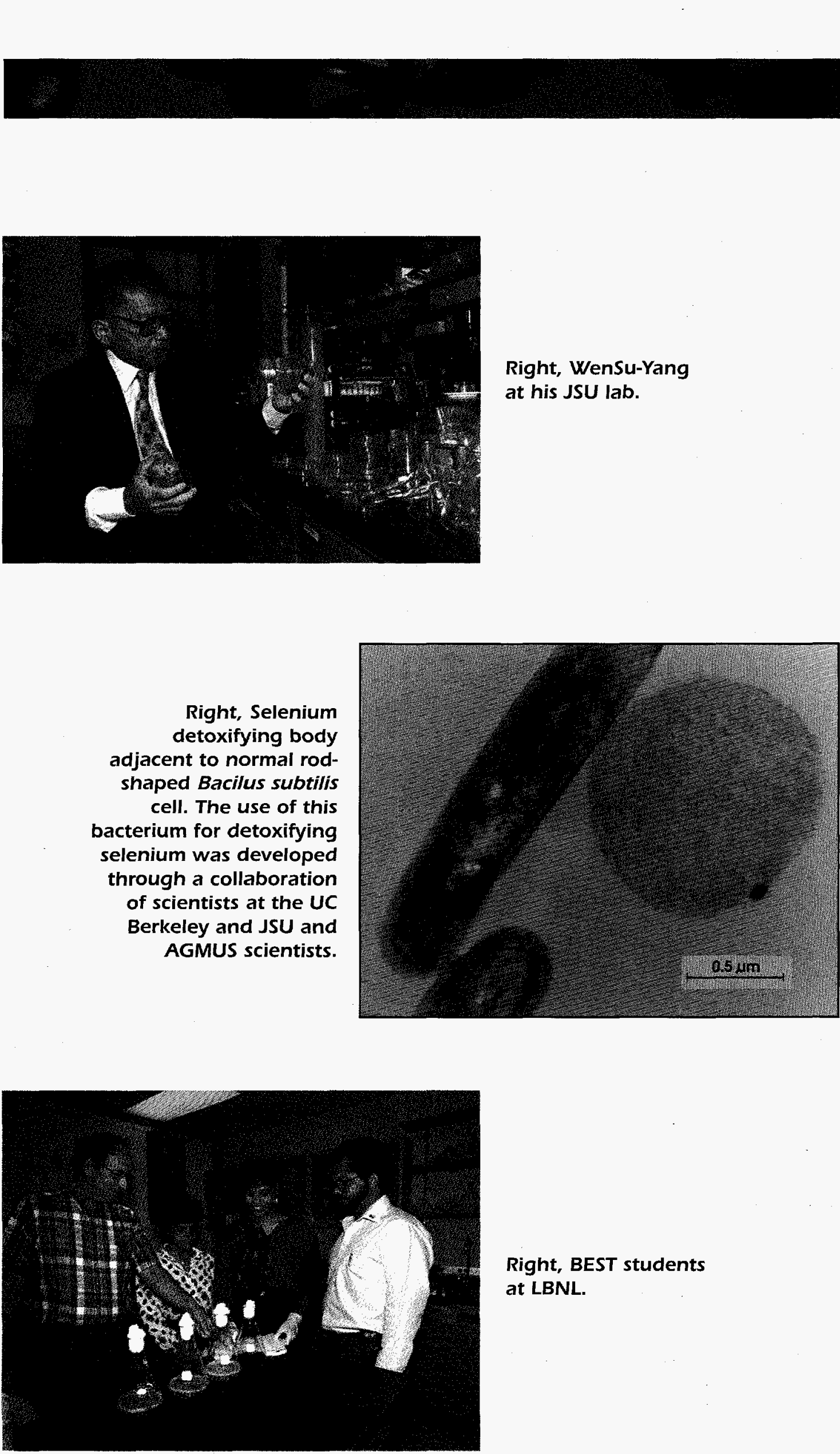

Right, BEST students at LBNL. helping the environment."

- Adis Y. Umpierre, Universidad

Metropolitana, 1994

graduate. 
A decade ago, JSU lacked the necessary computers and laboratory equipment to effectively support its bachelor of science programs. Now, the school is offering the doctorate degree in Environmental - Sciences. The School of Science and Technology has also expanded its curriculum to offer courses in cryptography, mathematical modeling and biotechnology. The com- puter science curriculum has been reviewed and restructured. Lawrence Berkeley National Laboratory has provided VAX computer terminals and computer science staff, bringing JSU's computing resources up to date. The university now offers seminars in the use of information networks.

The Science Consortium offers important resources for institutions that are in-

terested in developing science curricula. It maintains a comprehensive curriculum development resource library. It also provides models for curriculum development. Its work has spurred the growth of a community of scientists who are committed to sharing their knowledge through seminars and lectures at minority institutions.

- JSU development of the Ph.D. in Environmental Science - currently 30 students are enrolled

- AGMUS development of Turabo's B.S. in Chemistry

- Seminars and short courses at JSU and AGMUS

- Luis Feliú's collaboration with LBNL contributed to curriculum development: High Performance Liquid Chromatography - Organic Studies

- Colegio Universitario del Este - A.S. in natural sciences, pharmacy assistance, radiologic, medical records, ultrasound diagnosis and computerized tomography technology.

- Universidad Metropolitana - A.S. in general science, computer science, and nursing, and B.S. in biology, computer science, general natural science, nursing, respiratory therapy, and sales and distribution of pharmaceutical and chemistry products.

- Universidad del Turabo - B.S. in biology, chemistry, applied mathematics, and natural sciences.

- M.S. degree program in Hazardous Material Management was approved at JSU. 


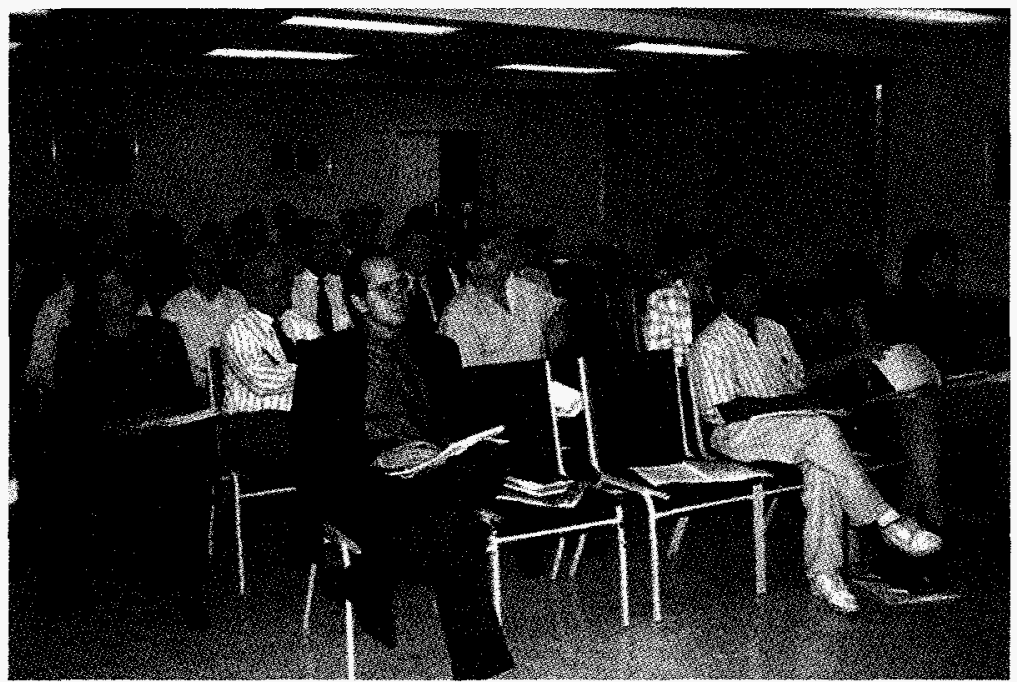

Above, AGMUS faculty at meeting.

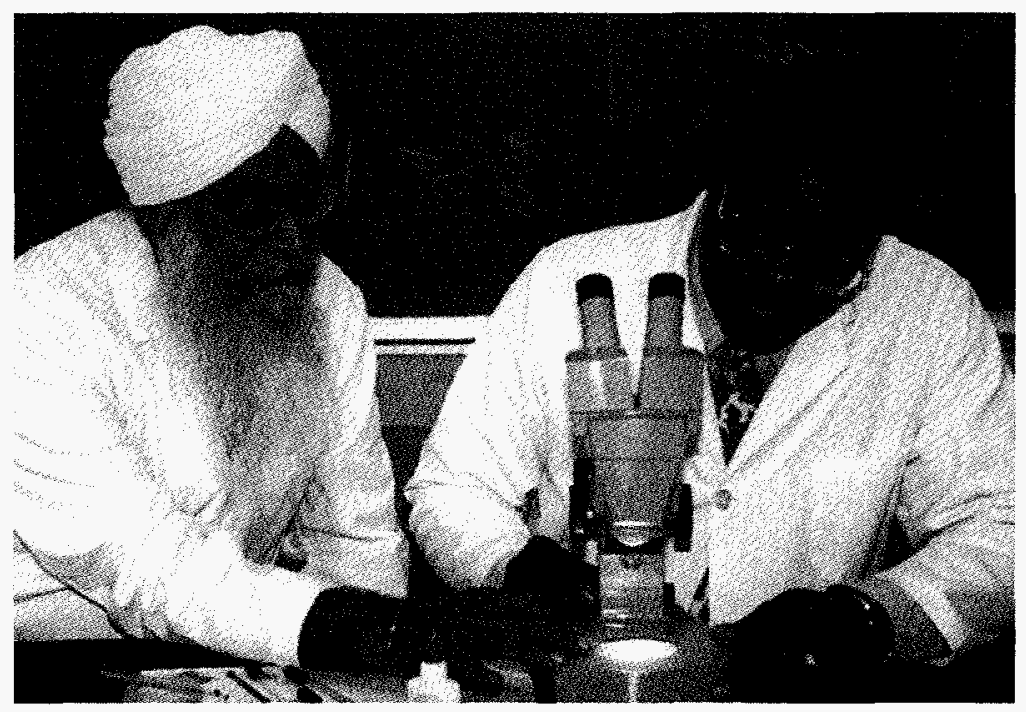

Above, JSU faculty and student.

"It is through the support of your office that I have obtained the necessary training to be competitive in the area of molecular biology."

- Barbara

Chapman, JSU graduate, medical technologist at Silas Beach Hayes

Hospital.

HIII!. 


\section{Precollege Programs}

n 1983, none of the schools of science and technology in the Science Consortium conducted Precollege outreach activities. Now, the Consortium reaches hundreds of teachers and students with programs at all its member institutions. The hope is to increase the number of incoming freshmen that have the potential to carry their interest in science into a career or into post-graduate studies.

- Comprehensive Activities to Upgrade Science Academics (CAUSA) was established through the Carnegie Foundation to help develop the precollege programs of the Science Consortium at AGMUS. Since 1984, more than 2,000 students have participated, and many have been accepted to top universities. Of these CAUSA graduates, 77I have chosen science-math based programs. Of the total students, 74I CAUSA graduates have expressed a desire to pursue graduate studies after their undergraduate experience. Approximately 50 teachers, 9 laboratory technicians, 7 counselors, 6 tutors, and I coordinator have participated each year.

- In 1990, Great Explorations in Math and Science (GEMS) began at the Lawrence Hall of Science. Puerto Rican high school teachers attending this program translated modules into Spanish and adapted them for use in high school biology classrooms in Puerto Rico.

In 1991, a pre-freshman engineering program started at Turabo University and in-service teacher programs started at Metropolitan University, strengthening instruction in Puerto Rico's public schools.

- In 1991, the Consortium initiated a precollege program at UT and UMET-both
AGMUS schools. The programs are oriented to increase the number and quality of undergraduate minority students entering the science and technology fields.

- In 1993, 90 high school students attended the precollege program at Turabo University and 45 students attended the program at Metropolitan University. Twenty three of a total 135 participants (17\%) applied to one of the science and technology programs offered by AGMUS.

- The Mississippi QEM Network Alliance was formed in the spring of 1991. It includes representatives from universities, precollege educational systems, business and industry, government, and community/professional organizations.

- Beginning in 1990, special emphasis was placed on Summer Residential Science Academies, a precollege initiative of the School of Science and Technology. This program includes follow-up during the academic year. Since 1990, the program has supported approximately 250 middle school and high school participants, 12 counselors, and 16 instructors. A Parent Advisory Group was formed in the summer of 1992 to support the precollege program.

- The School of Science and Technology received $\$ 1,180,000$ from the National Science Foundation for a "Comprehensive Regional Center for Minorities Program" to increase the number of Mississippi minority students studying math and science in middle/high school and those choosing to major in math and science in college. The funding period is from September I, 1993 to August 31, 1995. 


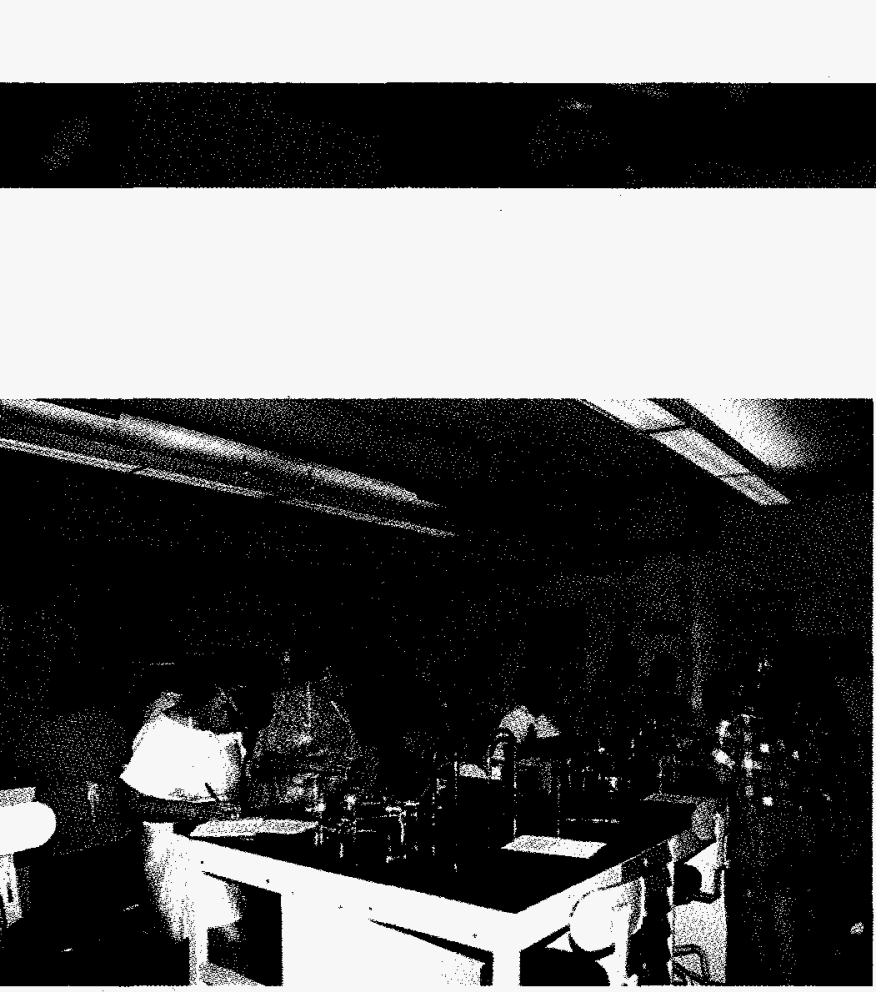

Left, Pre-college

program at Universidad

Metropolitana under

the supervision of Dr.

Doris Caro.

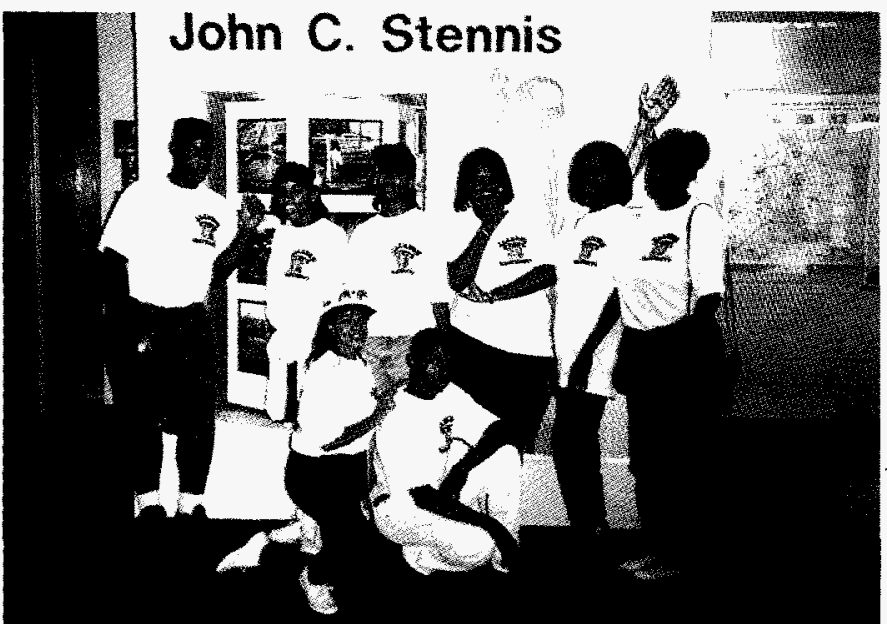

Left, Pre-college

participants on field trip at John C. StennisNASA Space Center.

Left, LBNL's pre-

college activitiy.

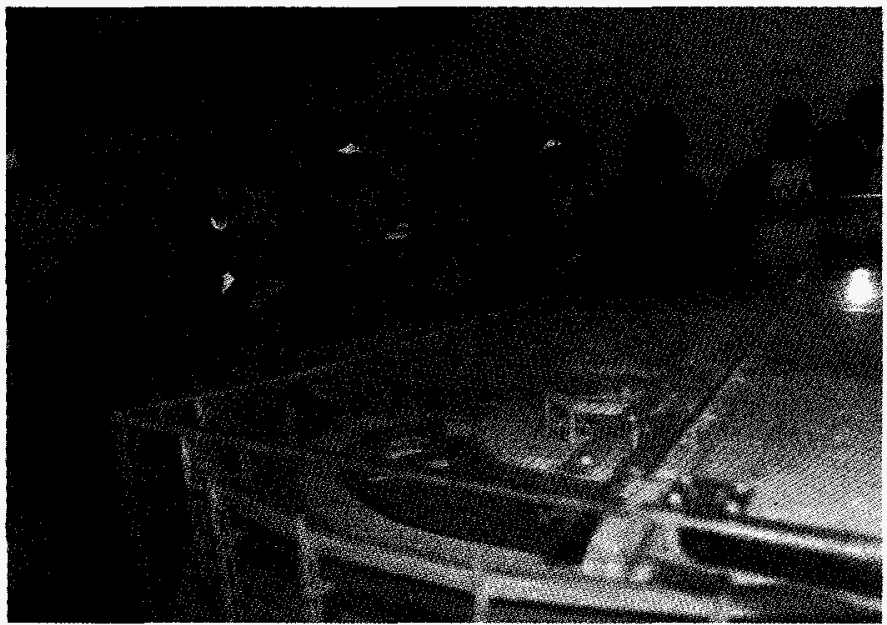




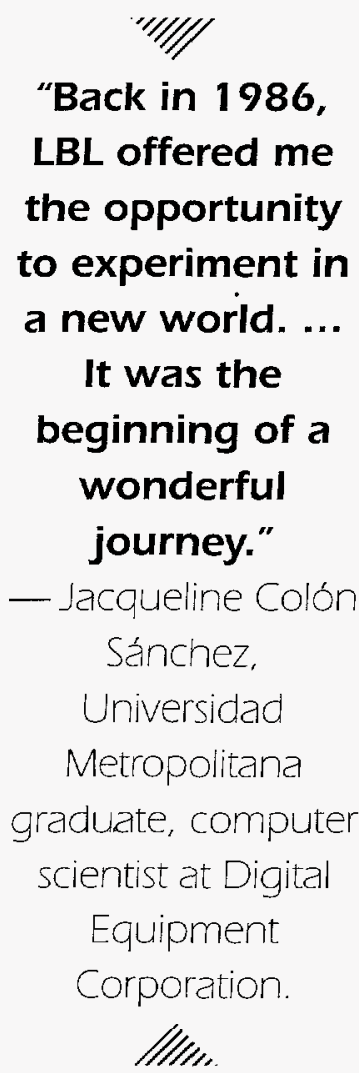

"Back in 1986 ,
LBL offered me
the opportunity
to experiment in
a new world. ...

It was the beginning of a wonderful journey."

Sánchez.

Universidad Metropolitana graduate, computer Equipment IIII!n. Infrastructure he Science Consortium has been crucial in the efforts of JSU and AGMUS to improve and enhance teaching and research, laboratory and computer facilities, and library resources. JSU and AGMUS developed computing and networking capability to support scientific research and science and technology education. AGMUS has facilities for faculty and student research. JSU and AGMUS have state-of-the-art computing systems. By 1994, both institutions had local area networks, and many faculty members were using the Internet.

- A five-year plan was prepared to define and broaden the Consortium's focus through outreach to other institutions and partnerships.

Above, a laboratory at Universidad del Turabo.

- The Consortium supported consultants to assist in the design and development of AGMUS's new science building, which was inaugurated in

1990. This building contains the organic, analytical, and environmental chemistry laboratories, and the molecular biology laboratories.

- AGMUS and JSU increased considerably their library holdings, especially their collections of scientific journals.

- Local area network and connectivity to Internet was supported by the Science Consortium at AGMUS.

- Internet connectivity was established at JSU.

- The Consortium worked with other JSU science and technology partnerships to establish and pay for implementation of JSU's local area network.

Left, a laboratory at JSU. 


\section{Reaching out to the Future}

$T$ he Science Consortium made remarkable progress in the eleven years of its existence. Its member institutions gained new capabilities, and their students and staff made good use of the opportunities created.

What we have developed over the years is an efficient collaborative model that has provided access to information and equipment as well as opportunities. The programs of the Science Consortium can now theoretically aid a single student from his or her first contact with the sciences through postgraduate research.

Through this comprehensive pipeline, we ultimately produce more minority scientists and engineers to meet the scientific challenges of the future.

As we begin our second decade, we are setting our sights on a broader approach. The Consortium is gearing its future activities toward reaching out to other minority institutions. We feel that the advancements made at our member institutions should be pursued at others like them. As we expand our scope, we can reach out to even more students, effectively increasing the flow of students in the science pipeline.

Our efforts to date have shown that sharing resources through a collaborative model works. Others have recognized this and modeled their own programs after ours. What is more, the Science Consortium itself has begun to generate new organizations based on the collaborative approach. Establishing new collaborations with other institutions continues this trend of reaching out, ultimately helping more and more students to find fulfilling careers in the sciences.

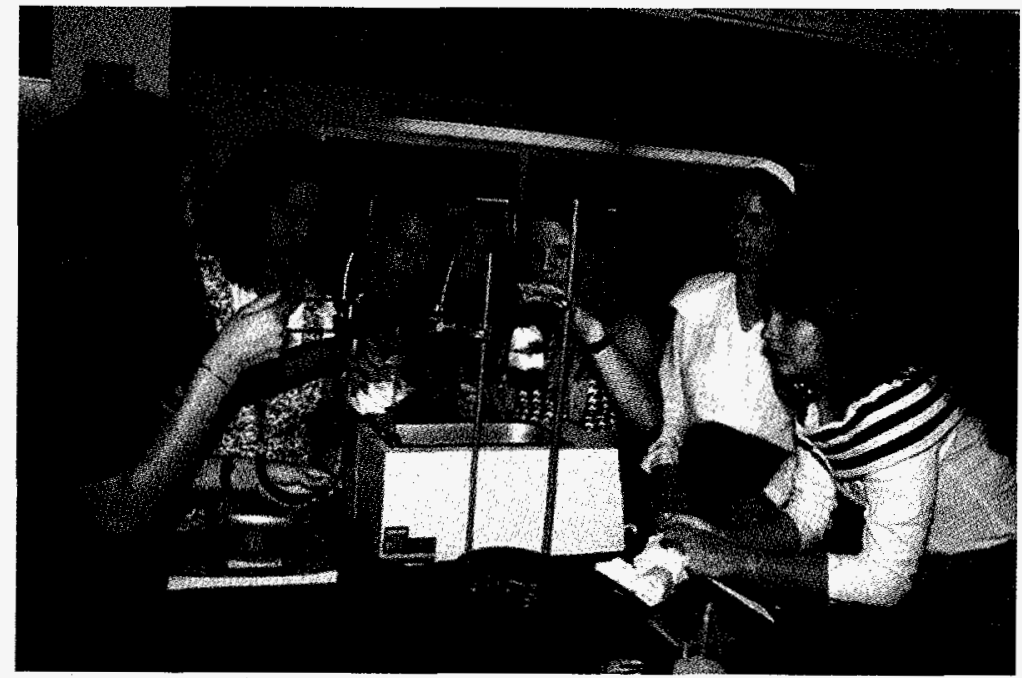

Above, a group of UMET students at one of its science laboratories.

years of olishments

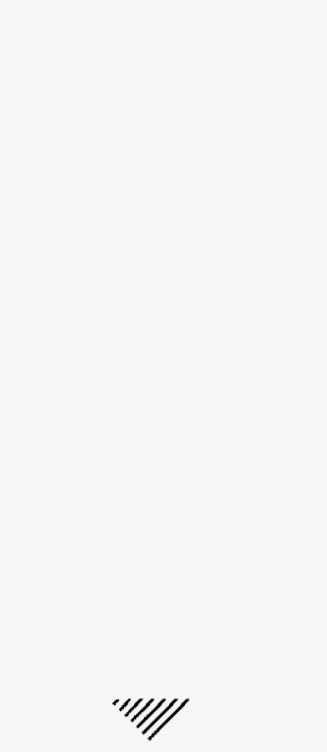

"When I first arrived at LBL, I was somewhat apprehensive about my abilities. When I left LBL, I believed there was nothing I couldn't do." - Michael Garner.

JSU graduate, computer scientist at AT \& T Bell Laboratories. IIIIr. 


\title{
Science Consortium Founders
}

John Peoples, former

President of JSU-The

School of Science \&

Technology was

dedicated in his honor.

\author{
Walter Hartsough, \\ former Associate \\ Laboratory Director \\ for Engineering \\ and Technical \\ Services at
}

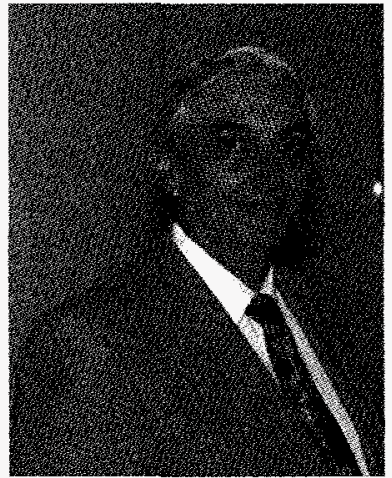

José F. Méndez, President of the Ana G. Méndez University System.

Harold Wilson, former head of minority student services at Lawrence Berkeley Laboratory.

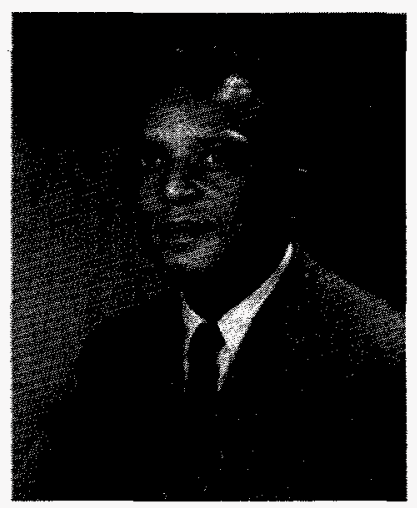

James Perkins, first

Dean of Jackson State University's School of Science and Technology. 


\section{Words from Key Science Consortium Supporters}

\section{Dr. Juan Bonnet}

Through the Consortium, there has been access to a pool of resources for faculty and student development, collaborative research, curriculum and infrastructure development.

\section{Dr. James Perkins}

The institutional changes at JSU and AGMUS have provided places of excellence in education and research where minority students can attend. The faculty of these institutions have a gateway for collaborative research with world class scientists in cutting edge areas of science and engineering. Many of these faculty are minorities who can make their presence and contributions known in scientific circles. Students attending JSU or AGMUS who have participated in this program have gone on for terminal degrees and will serve as role models for future generations of students of color at all levels of education.

\section{Ms. Miriam Cruz}

The two minority institutions have the opportunity to increase the number of students and they have diversified their academic programs. They also increased the number of advanced degrees among their faculty. The quality of their programs definitely has been strengthened are result of this.

\section{Mr. Harold Wilson}

JSU and AGMUS had different institutional goals and could not be treated like small liberal arts colleges. The Science Consortium influenced the way federal government agencies dealt with HBCUs and Mls. 


\section{Additional Publications}

- J.M. Pridemore, G.B. Begonia and M.L. Salin, "Characterization of an IronContaining Superoxide Dismutase from the Unicellular Alga, Chlamydomonas moewusiin." Plant Physiology (Life Sci.Adv.). 10:13 |-137; 1992.

- R. Karim, "A New Diagnostic Instrument for PBX-M Utilizing an Optical Multichannel Analyzer." Bulletin of the American Physical Society; 37(6), 1393; 1992.

- J. Lezcynski, "Tautomers of 6Thioguanine: Structures and Properties," Journal of Physical Chemistry; 97; 3520; 1993.

- J. Lezcynski, "Ab Initio Hartree-Fock and Post-Hartree-Fock Study of Molecular Structures and Vibrational Spectra of Thioformaldehyde and Its Fluoro, Chloro and Bromoderivatives." Journal of Physical Chemistry; 97: I845; 1993.

- J. Lezcynski, "Molecular Structures and Properties of Phosphine Selenide and Seneopho-sinous Acid Revealed by ab initio Post-Hartree-Fock Studies." Journal of Physical Chemistry, 97; I364; 1993.

- J. Lezcynski, "Molecular Structures and Vibrational Spectra of Selenoketene and Its Thio- and Oxo-Analogs by ab initio Post-Hartree-Fock Study." Chemical Physics Letters. 901; 79; 1993.

- J. Lezcynski, "Harmonized Infrared Spectrum of Formaldehyde: Experiment and Theory." Journal of Molecular Spectroscopy. 157: 540; 1993
- J. Lezcynski, "Temperature-Dependent Thermodynamic Contributions to the Relative Tautomeric Stabilities of Nucleic Acid Bases." Chemical Physics Letters. 204:430; 1993.

- H.R. Shih. "Approximation and Substructuring Techniques in Structural Optimal Design Using Boundary Elements." Computer Applications and Design Abstraction; 49: I I 1-1 16; 1993.

- E. Noe. "Conformational Studies of Alkyl Nitrites Using Low-Temperature ${ }^{13} \mathrm{C},{ }^{17} \mathrm{O}$ and ${ }^{14} \mathrm{~N}$ NMR Spectroscopy. ${ }^{17} \mathrm{O} N M R$ of N-Substituted Formamides." Journal of Chemical Physics. (In Press)

- J. Leszczynski \& L. Goodman. "Importance of Polarization and Correlation Effects in Ab Initio Prediction of the Acetaldehyde Methyl Torsional Barrier." Journal of Chemical Physics. 99, 4867, 1993.

- J. Leszczynski and J. S. Kwiatkowski. "Molecular Structure and Vibrational IR Spectrum of Formamide Revisited: Ab Initio Post-Hartree-Fock Study." Journal of Molecular Structure; 297, 277; 1993.

- Hui-Ru Shih and V. Brewer. "Development of an Experimental Method to Determine the Axial Rigidity of a Strut Node Joint." NASA CP-3201; Pp. 37 41, 1993.

- Hue-Min Hwang, R. Hodson, D. Lewis, and R. Scholze. "Microbial Activity in Ground Water at a Chemical Waste Disposal Site." Bulletin of Environmental Contamination and Toxicology; 1993. 
For further information about the LBNL/JSU/ AGMUS Science Consortium, please contact:

\section{Mr. Gerald R. Davis}

Executive Administrator, Science Consortium Lawrence Berkeley National Laboratory

I Cyclotron Rd., MS 938-C

Berkeley, CA 94720

(5 I0) 486-4858

e-mail: grdavis@|bl.gov

\section{Mr. Shelton Swanier}

Assistant to the Dean, Coordinator

Jackson State University

I400 J.R. Lynch Street

Jackson, MS 39217

(60I) $968-2312$

e-mail: sswanier@ccaix.jsums.edu

Dr. María de los A. Ortiz

Vice President for Academic Affairs and Director of Science Consortium

Ana G. Méndez University System

Call Box 21345

Río Piedras, PR 00928

(809) $751-0178$, ext. 7218

e-mail: ac_maortiz@suagm l.suagm.edu 
Lawrence Berkeley National Laboratory

Center for Science and Engineering Education

University of California

Berkeley, California 94720

\section{DISCLAIMER}

This document was prepared as an account of work sponsored by the United States Government. While this document is believed to contain correct information, neither the United States Government nor any agency thereof, nor The Regents of the University of California, nor any of their employees, makes any warranty, express or implied, or assumes any legal responsibility for the accuracy, completeness, or usefulness of any information, apparatus, product, or process disclosed, or represents that its use would not infringe privately owned rights. Reference herein to any specific commercial product, process, or service by its trade name, trademark, manufacturer, or otherwise, does not necessarily constitute or imply its endorsement, recommendation, or favoring by the United States Government or any agency thereof, or The Regents of the University of California. The views and opinions of authors expressed herein do not necessarily state or reflect those of the United States Government or any agency thereof, or The Regents of the University of California.

Lawrence Berkeley National Laboratory is an equal opportunity employer. Pub-766 - 8/95

Printed on recycled stock. 